\title{
Design, processing and characterization of titanium with radial graded porosity for bone implants
}

\author{
Y. Torres a , P. Trueba a , J.J. Pavón ${ }^{\text {b }}$, E. Chicardi c,* P. Kamm ${ }^{\text {d }}$, F. García-Moreno d , J.A. Rodríguez-Ortiz ${ }^{\text {a }}$ \\ a Department of Engineering and Materials Science and Transportation, University of Seville, Av. Camino de los Descubrimientos s/n, 41092 Seville, Spain \\ b Group of Advanced Biomaterials and Regenerative Medicine, BAMR, Bioengineering Program, Universidad de Antioquia, Calle 67 No. 53-108, Medellin, Colombia \\ ' Univ. Tecn. Federico Santa María, Dept. Ing. Met. E Mat., Av. España 1680, Valparaíso, Chile \\ ${ }^{\mathrm{d}}$ Helmholtz-Zentrum Berlin für Materialien und Energie, Hahn-Meitner-Platz 1, 14109, Berlin, Germany
}

\section{H I G H L I G H T S}

- A compaction device was developed to obtain radial graded porosity Ti cylinders, suitable for biomedical applications.

- The powder metallurgy space-holder technique was applied for that purpose, guaranteeing the structural integrity of the Ti cylinders.

- The microstructure obtained is a new bio-inspired/biomimetic approach to solve the bone resorption due to the stress-shielding phenomenon.

\section{A R T I C L E I N F O}

\section{Article history:}

Received 13 May 2016

Received in revised form 27 July 2016

Accepted 28 July 2016

Available online 30 July 2016

\section{Keywords:}

Biomaterials

Functionally graded materials (FGM)

Microtomography

Porous material

Space-holder technique

Stress shielding

\section{GR A P H I C A L A B S T R A C T}

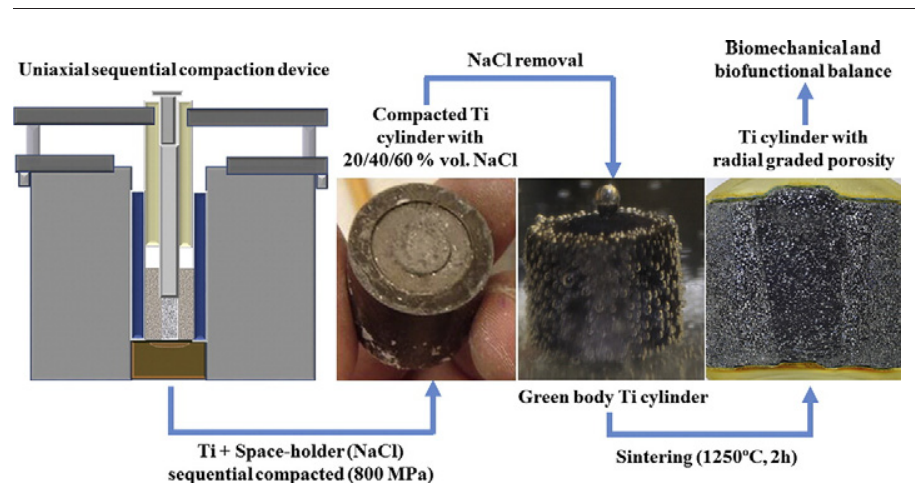

\section{A B S T R A C T}

Titanium cylinders with radial graded porosity, which are potentially suitable for biomedical applications (replacement of cortical and trabecular bones involved in different joint and dental restorations), have been developed by a novel uniaxial and sequential compaction device, based on powder metallurgy techniques. The macrostructural, microstructural and mechanical properties of the cylinders were characterized. The microstructure obtained is a new bio-inspired/bio-mimetic approach to solving one of the most important drawbacks of titanium implants, i.e., bone resorption due to the stress-shielding phenomenon. In addition, the developed device has proved to have unique advantages in customizing the structural integrity in conventional powder metallurgy manufacturing in a simple, economic and reproducible manner.

(c) 2016 Elsevier Ltd. All rights reserved.

\section{Introduction}

Musculoskeletal diseases are currently recognized as an important health problem in society, as reported by the World Health Organization

\footnotetext{
* Corresponding author.

E-mail address: ernesto.chicardi@usm.cl (E. Chicardi).
}

(WHO) [1]. Within this context, there is a remarkable growth in demand for bone implants and prostheses, due to increased life expectancy, traumatic accidents, aesthetic dental factors, etc. [2]. Additionally, a high percentage of current bone implants fail during the first 10 years, and $20 \%$ of new implants are used to replace those that have failed [3]. Accordingly, it is desirable to develop new technologies that improve overall performance of implants and prostheses. 
The suitability of materials for bone tissue replacement is imposed by two main parameters: biocompatibility and corrosion resistance in the presence of biological fluids [4-6]. Based on these criteria, titanium (Ti) and its alloys are widely applied in biomedical fields such as bone implantation [7,8]. Both kinds of materials exhibit a suitable in vivo performance acting as bone replacements [9-11], with reasonably good osseointegration $[12,13]$. However, they also present an important drawback associated with the significant difference between their Young's modulus, E (100-110 GPa for commercially pure Ti and $\sim 114 \mathrm{GPa}$ for Ti6Al4V) and the corresponding value of the bone to be replaced (20.7-18.6 GPa for cortical bone and 14.8-10.4 GPa for trabecular bone [14]). This difference implies an inefficient load transfer between bone and implant, which is known as the stress shielding phenomenon [15]. This elasticity mismatch causes an increase in induced bone resorption, which diminishes the density of adjacent bone and, consequently, generates a higher risk of fracture with the undesirable associated aseptic loosening of bone implants.

Important research and technological efforts have been dedicated to solving stress shielding problems during the last decade. Specifically, some previous works have been focused on developing polymer matrix composites, fully densified metal materials (stainless steel $316 \mathrm{~L}, \mathrm{Cr}-\mathrm{Co}$, Mn and $\beta$-Ti metastable alloys), porous metal materials ( $<70 \mathrm{vol} . \%$ of porosity) and foams ( $>70$ vol.\% of porosity), among others [16-22]. These last two types of materials, with a custom-made porosity, allow the Young's modulus of the implants to be modulated by the control of pore size, morphology, distribution and amount of porosity. In this context, some techniques are usually employed to produce porous biomaterials. Their study and evaluation have been undertaken by many authors, with the works of Banhart, Betts, Singh, and Bansiddihi [23-26] being highlighted. Among those works, sintering methods, such as conventional powder metallurgy [27-29] and pressure-assisted sintering (spark plasma sintering, hot pressing, hot isostatic pressing), by using blowing agents or space-holder technique [24,30,31], are widely used. The latter is based on the co-pressing of a metal powder with another powder, called "space-holder" (carbamides, ammonium bicarbonate, sodium chloride, potassium carbonate, polymethylmethacrylate, etc.), which is easily removable, either by leaching or evaporation. Similarly, the pressure infiltration of a bed of leachable particles by a liquid metal, followed by leaching to leave a metal-sponge skeleton, is also used [32].

The reduction of the stress shielding phenomena and the mimicry of a highly hierarchical bone structure are factors closely related in the sense of developing advanced implants. These two factors must be considered to ensure a balance between biofunctional and biomechanical properties. However, achieving that goal remains a challenge today, and designing and developing functionally graded materials (FGM) with an on-demand porosity, has emerged as a promising alternative [33]. In the context of this new approach, only a few works can be found in the literature $[34,35]$. However, their attempts have several limitations in terms of the graded porosity design (amount, pore size and distribution), influence of processing parameters, and evaluations of in-service performance (Young's modulus, mechanical strength and bone ingrowth).

The aim of this work is to develop and characterize samples of commercially pure titanium (c.p. Ti) with a functionally radial graded porosity (as occurs in the bone tissues), according to bio-inspired and bio-mimetic approaches, for potential bone implant applications. The samples were designed with a radial graded porosity of 20,40 and 60 vol.\% in three layers, i.e., the core, the inner shell and the outer shell, respectively, using space-holder technique and a novel compaction device developed by the authors.

\section{Experimental}

\subsection{Materials and graded porosity design}

Commercially pure titanium grade 4 (c.p. Ti. Grade IV, according to ASTM F67-13, SE-JONG Materials Co. Ltd., Korea) and sodium chloride
( $\mathrm{NaCl}$, Panreac Química, S.A.U., Spain, purity >99.5\%) were used as the starting powders. The Ti powder exhibited an irregular morphology and particle sizes of 9.7, 23.3 and $48.4 \mu \mathrm{m}$, corresponding to the $\mathrm{P}_{10}$, $\mathrm{P}_{50}$ and $\mathrm{P}_{90}$ percentiles. The $\mathrm{NaCl}$ powders, employed as space-holder, were ground for $30 \mathrm{~min}$ in a Turbula ${ }^{\circledR} \mathrm{T} 2 \mathrm{C}$ Shaker-Mixer with tempered $\mathrm{Cr}$-Steel balls (67 HRC) of $4.65 \mathrm{~mm}$ diameter, and a powder-to-ball mass ratio (PBR) equal to $1 / 2$. Afterwards, they were sieved to obtain $\mathrm{NaCl}$ particles of between $100 \mu \mathrm{m}$ and $200 \mu \mathrm{m}$, which showed regular cubic morphology and an average particle size of $154 \pm 30 \mu \mathrm{m}$. NaCl particles were used as space-holder due to their low cost, easy dissolution, and non-residual toxicity. Both materials were selected according to some specific criteria: firstly, the low particle size of Ti powder was selected to improve the sintering due to a greater contact between particles; secondly, the distribution and average size of $\mathrm{NaCl}$ space-holder particles, between 100 and $200 \mu \mathrm{m}$, should contribute to achieving an important interconnected porosity and open cell surface, ensuring bone ingrowth into the implant [36]. Also, the average $\mathrm{NaCl}$ particle size was chosen to increase the reliability of the implants, by avoiding the high porosity associated with large particle size, which would be detrimental for mechanical strength.

\subsection{Preparation of specimens}

The mixtures of c.p. Ti and the 20, 40 and $60 \mathrm{vol} . \%$ of $\mathrm{NaCl}$ were obtained by using the same Turbula ${ }^{\circledR}$ T2C Shaker-Mixer, without any grinding media. In order to ensure optimal homogenization, each mixture was homogenized for $40 \mathrm{~min}$. Subsequently, the mixtures were cold compacted uniaxially by using a U30 (Malicet \& Blin M.A.B.) hydraulic press at the optimum pressure of $800 \mathrm{MPa}$ applied at $98.1 \mathrm{~N} / \mathrm{s}$ for 2 min, according to previous work [37]. The specimens of green $\mathrm{Ti}$ cylinders with radial graded porosity (henceforth Ti cylinders), were obtained with a diameter of $20 \mathrm{~mm}$ and a height of $18 \mathrm{~mm}$, approximately. The nominal composition characteristics (porosity, percentage of $\mathrm{NaCl}$ and $\mathrm{Ti}$ and the relative volume) of each zone that formed the Ti cylinders are depicted in Table 1.

The compacting process of the Ti cylinders was carried out in three steps, using a novel compacting device (Fig. 1). This device is composed of the following set of elements: a) an external die and the base of the device; b) a compression system, with three punches and sleeves used for the core, inner and outer shell compaction processes; and, c) an ejection system that consists of another set of punches for each of the core, inner and outer shell zones.

Thus, the process of shaping the Ti cylinders consisted of the following sequential steps $(\mathrm{a}-\mathrm{c})$ :

a) Core compaction: the external die, the lower base and the external and internal sleeves are positioned. The remaining empty internal zone (core) is filled with the corresponding powder mixture ( 80 vol.\% c.p. $\mathrm{Ti}+20 \mathrm{vol} . \% \mathrm{NaCl}$ ). Then, the core is compacted using the internal punch. The green body of the core is subsequently removed with an ejection system.

b) Inner shell compaction: the external die, the lower base, the external sleeve and the green body of the core, under its corresponding punch, are now positioned; the punch must be centered with the slot made in the lower base. Again, the remaining empty intermediate zone is filled with the corresponding powder mixture (60 vol.\%

Table 1

Nominal compositional characteristics of each zone of the Ti cylinder formed with radial graded porosity.

\begin{tabular}{llll}
\hline & Core & Inner shell & Outer shell \\
\hline $\mathrm{NaCl}$ (vol.\%) & 20 & 40 & 60 \\
$\mathrm{NaCl}$ (wt.\%) & 12.7 & 24.3 & 41.9 \\
$\mathrm{Ti}$ (wt.\%) & 87.3 & 75.7 & 58.1 \\
Relative volume (\%) & 16.1 & 33.0 & 50.9 \\
\hline
\end{tabular}



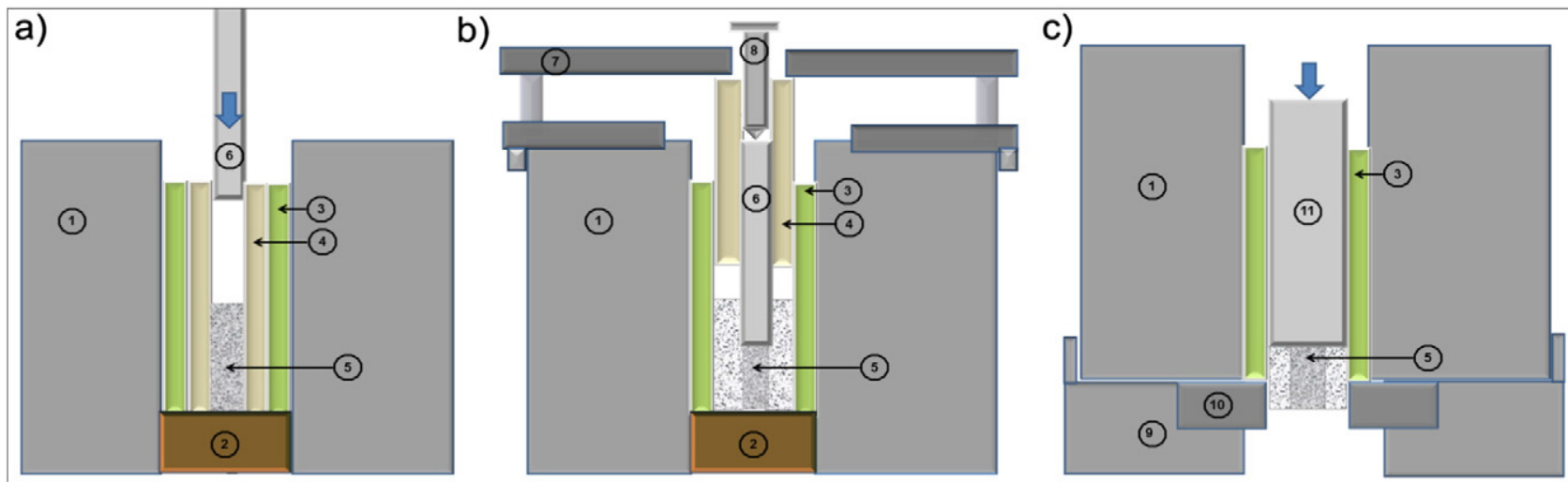

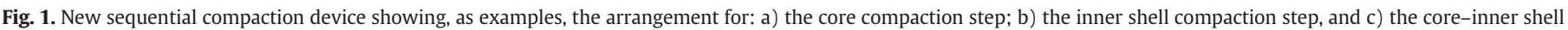

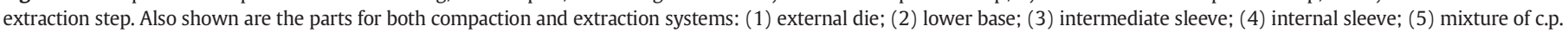

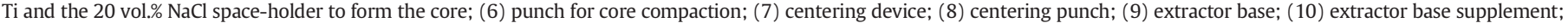
(11) extractor punch.

c.p. $\mathrm{Ti}+40 \mathrm{vol} \% \mathrm{NaCl}$ ). Then, the inner shell is compacted with the intermediate punch. Once compacted, the compression system is replaced by that for extraction, and the new green body formed by the core and the inner shell is extracted.

c) Outer shell compaction: all external dies, the lower base and the green body piece are positioned in the geometrical center of the lower base, together with their corresponding punches. The remaining empty external shell is filled with the last powder mixture ( 40 vol.\% c.p. $\mathrm{Ti}+60$ vol.\% $\mathrm{NaCl}$ ). The external punch is then used to compact the outer shell. The extraction process is repeated, as in steps a) and b). Subsequently, the green body-piece formed by a core, an inner shell and an outer shell is obtained.

To lubricate both the die and the sleeve walls, Ethlyne-BisStearamide (EBS) wax is used during the compaction steps. After each of the three compaction stages, the wax is removed by a two-step degasification process: at $300{ }^{\circ} \mathrm{C}$ and $500{ }^{\circ} \mathrm{C}$, with a heating rate of $5^{\circ} \mathrm{C} / \mathrm{min}$ for $2 \mathrm{~h}$ each step, and under high vacuum $\left(\sim 10^{-5} \mathrm{mbar}\right)$ in order to avoid a probable delamination between layers during the sintering process [35].

In the next step, the space-holder, $\mathrm{NaCl}$, must be suitably removed from the green body. During this process, the structural integrity of the green bodies must be preserved. This process uses a protocol which was optimized in previous works [37-39]. The protocol consists of several immersions of the $\mathrm{Ti} / \mathrm{NaCl}$ green bodies in static distilled water over $24 \mathrm{~h}$, at temperatures between $45{ }^{\circ} \mathrm{C}$ and $55^{\circ} \mathrm{C}$. To avoid $\mathrm{NaCl}$ saturation, and to facilitate $\mathrm{NaCl}$ removal, the distilled water was replaced every $2 \mathrm{~h}$, without handling the specimens to reduce undesired separation of the powders. During $\mathrm{NaCl}$ removal, the mass loss was evaluated every four hours, once the samples were dried for $2 \mathrm{~h}$ in an oven at $110{ }^{\circ} \mathrm{C}$

Finally, the Ti cylinders were sintered in a ceramic furnace tube (Carbolyte ${ }^{\circledR}$ STF $15 / 75 / 450$ ) at $1250{ }^{\circ} \mathrm{C}$ for $2 \mathrm{~h}$ under high vacuum $\left(\sim 10^{-5} \mathrm{mbar}\right)$ with a heating rate of $10{ }^{\circ} \mathrm{C} / \mathrm{min}, 5{ }^{\circ} \mathrm{C} / \mathrm{min}$ and $1{ }^{\circ} \mathrm{C} / \mathrm{min}$ up to $1200{ }^{\circ} \mathrm{C}, 1245^{\circ} \mathrm{C}$ and $1250{ }^{\circ} \mathrm{C}$, respectively, to avoid temperature jumps close to the sintering temperature. Moreover, intermediate dwell times were applied at $500{ }^{\circ} \mathrm{C}(60 \mathrm{~min}), 800{ }^{\circ} \mathrm{C}$ (30 $\mathrm{min}$ ) and $1000{ }^{\circ} \mathrm{C}(30 \mathrm{~min})$ to facilitate interface bonding, removal of remaining wax and achieving the high vacuum.

It is important to emphasize that four specimens of Ti cylinders with the same design in terms of microstructure, size and radial graded porosity were produced to ensure the reproducibility of the full process, i.e., mixing of powders, compaction and space-holder removal steps. Also, this allowed the standard deviation for all determined microstructural parameters and mechanical properties to be obtained.

\subsection{Physical and microstructural characterization}

Measurements of Ti cylinder density were performed using Archimedes' method by immersions in distilled water (ASTM C373-14 Standard). The method was selected mainly for the feasibility of the protocol. Total and interconnected porosities were calculated from those density values [40].

In addition, the porosity and the equivalent pore diameter $\left(D_{\text {eq }}\right)$ values of each layer (core, inner shell and outer shell) were estimated by Image Analysis (IA). The IA technique was performed through a protocol (Panorama Maker ${ }^{\circledR}$ and Adobe Photoshop ${ }^{\circledR}$ ) of 10 images for each zone $(5 \times)$. The images were captured by using a Nikon Epiphot optical microscope (Nikon, Tokio, Japan) coupled with a Jenoptik ProgRes ${ }^{\circ}$ C3 camera (Jenoptik, Jena, Germany). In order to obtain optimal images, a conventional metallographic preparation of the specimen was necessary, including resin mounting, grinding and mechano-chemical polishing with magnesium oxide $(\mathrm{MgO})$ and hydrogen peroxide $\left(\mathrm{H}_{2} \mathrm{O}_{2}\right)$

Also, X-ray diffraction (XRD) patterns of the sintered Ti cylinder with radial graded porosity were obtained on the same specimen with the metallographic preparation and using a PANalytical X'Pert Pro instrument equipped with a $\theta / \theta$ goniometer, a $\mathrm{Cu} \mathrm{K}_{\alpha}$ radiation source $\left(40 \mathrm{kV}, 40 \mathrm{~mA}\right.$ ), a secondary $\mathrm{K}_{\beta}$ filter and an $\mathrm{X}^{\prime}$ Celerator detector. The diffraction patterns were collected from $20^{\circ}$ to $70^{\circ}(2 \theta)$ in a step-scan mode at a step of $0.02^{\circ}$ and a counting time of $275 \mathrm{~s} / \mathrm{step}$, and were compared with those in the PDF-4 + database from the International Centre for Diffraction Data (ICDD).

Furthermore, the morphology and macrostructure were characterized using X-ray micro computed tomography (CT). For this purpose a custom-made X-ray scanner was used, composed mainly of a microfocus X-ray source L8121-01 (with a W-target ) from Hamamatsu, Japan, operated at $100 \mathrm{kV}$ and $100 \mathrm{~mA}$, and a flat panel detector C7943 (120 mm $\times 120 \mathrm{~mm}, 2400 \times 2400$ pixel), also from Hamamatsu. A $3 \mathrm{D}$ volume of the specimen can be obtained by acquiring a certain number of X-ray projections during sample rotation over $360^{\circ}$, followed by software reconstruction of these projections. This method allows the qualitative and quantitative exploration and analysis of the interior structure of the porous Ti samples, with a spatial resolution down to $6.4 \mu \mathrm{m}$ pixel size, in terms of pore size distributions, porosity, etc. For that purpose, a quarter of the cylinder was cut and imaged. The reconstructed volume was subjected to image analysis, including a series of filtering, separation and segmentation steps to obtain a quantitative analysis of porosity and equivalent diameter. Pores at the interface between core, inner and outer shell were removed virtually for the analysis to avoid border effects. A volume of $2 \mathrm{~mm} \times 2 \mathrm{~mm} \times 1 \mathrm{~mm}$ from each region was analyzed. 


\subsection{Mechanical behavior}

The mechanical characterization of the Ti cylinders involved the uniaxial compression tests and the estimation of the dynamic Young's modulus $(E d)$. The uniaxial compression tests were carried out with a universal Instron machine. The dimension of the Ti cylinder $(16 \mathrm{~mm}$. height and $20 \mathrm{~mm}$. diameter) was fixed according to the Standard for Mechanical testing of metals - ductility testing - compression test for porous and cellular metals (ISO 13314:2011), with a height/diameter aspect ratio of 0.8 [41]. The strain rate used was $0.005 \mathrm{~min}^{-1}$ and all tests were stopped when a strain level of $50 \%$ was reached. The yield strength (oy) and the Young's modulus were obtained from them.

The estimation of the dynamic Young's modulus (Ed) was carried out using the experimental values obtained for cylinders with homogeneous porosity of 20,40 and $60 \%$, corresponding to the porosity of each zone (core, inner shell and outer shell) in the Ti cylinder with radial graded porosity.

These experimental values were determined by the ultrasonic technique [37] and carried out using a Krautkramer USM 35(R) flaw detector. This method allows the transverse and longitudinal propagation velocities to be determined. To evaluate transverse waves, a Panametric S-V153(R) 1.5 MHz shear wave transducer with a wear shear couplant (Panametric-NTD(TM)) is used. For longitudinal waves, a Panametric S-NTD(R) $4 \mathrm{MHz}$ ultrasonic transducer with an ultrasonic couplant (Sonotrace grade $30(R)$ ) is employed. The Müller's mathematical equation [42] is used to determine the dynamic Young's modulus, once the acoustic wave velocities are measured.

The above experimental steps (design of the Ti cylinders with radial graded porosity and their microstructural and mechanical characterizations) allow the confirmation of the efficiency of both the uniaxial sequential compaction device and the $\mathrm{NaCl}$ removal, as well as the optimization of the sintering parameters. In addition, the proper choice of porosity (radial design, distribution of percentage porosity and size of pores) was tested in terms of the structural integrity of the core and inner shell required for cortical bone biomechanical compatibility and increased osseointegration.

\section{Results and discussions}

\subsection{Space-holder removal}

The space-holder $(\mathrm{NaCl})$ was removed from the Ti cylinders using the above mentioned protocol. The mass loss kinetics corresponding to $\mathrm{NaCl}$ removal, in terms of number of cycles ( $4 \mathrm{~h}$ per cycle), are presented in Fig. 2a. Moreover, the $\mathrm{NaCl}$ removal process for Ti cylinders with homogeneous porosities of $30 \mathrm{vol} . \%$ and $50 \mathrm{vol} . \%$ is also shown in the same Figure, to compare the effectiveness of the process. A steady state in the $\mathrm{NaCl}$ removal, which was reached after 4 cycles (16 h), was clearly observed. Even when the temperature of distilled water was increased by $10{ }^{\circ} \mathrm{C}$, from $45{ }^{\circ} \mathrm{C}$ to $55^{\circ} \mathrm{C}$, for the fourth cycle, the $\mathrm{NaCl}$ loss did not increase. The mass loss of $\mathrm{NaCl}$ was $5.03 \pm 0.09 \mathrm{~g}$, measured by the mass difference between the initial and the final weight, after $\mathrm{NaCl}$ elimination. This latter value corresponds to a $\mathrm{NaCl}$ removal of $\sim 93 \mathrm{wt}$.\% (initially $\mathrm{NaCl}$ was $5.43 \mathrm{~g} \pm 0.12$ ). The remaining $\mathrm{NaCl}$ percentage is removed during the later sintering process, and is then not an important concern for further applications. It must be pointed out that, during the $\mathrm{NaCl}$ removal process, some Ti particles were detached from the surface of the cylinders. However, that slight amount of Ti is negligible, as has been previously determined [37].

The process reached a stationary state for the Ti cylinders, in concordance with the Ti cylinders with $30 \mathrm{vol} . \%$ and 50 vol.\% of porosity. However, this stationary state for the $\mathrm{NaCl}$ removal process was reached earlier for the Ti cylinders, which indicates a positive effect of the interfaces (core-inner shell and inner shell-outer shell interfaces) on the $\mathrm{NaCl}$ removal process, due to the discontinuity generated in them. Thus, the higher porosity of these interfaces in comparison with the bulk zones caused a preferential path for the penetration of the water and exit for the dissolved $\mathrm{NaCl}$. Also, in this context, the higher the total porosity, the higher was the detected initial $\mathrm{NaCl}$ removal rate due to higher interconnectivity between $\mathrm{NaCl}$ particles.

Fig. 2b-d, at the final moment of the last removal cycle, demonstrates that structural integrity of all three samples (size, morphology, layers) was not sensitive to conditions of the removal process. This fact can be assumed as proof of the success and repeatability of the protocol.

This $\mathrm{NaCl}$ removal method allowed important features to be attained, such as reproducibility, removal effectiveness, simplicity, and, for keeping the samples morphologically intact. It has also proved to be both clearly reliable and cheap to apply for Ti designing with longitudinal [39], as well as with radial gradient porosity.

\subsection{The sintering process of samples, and their physical/microstructural characterization}

After $\mathrm{NaCl}$ removal, the Ti cylinders (Fig. 3a) were sintered under the previously described conditions. Fig. 3b illustrates the macro-aspect of a representative sintered specimen. This figure shows the three layers obtained with different porosities, i.e., the core, the inner shell and the outer shell. It should be noted that different heights are observed at the cylinder base between the layers (Fig. 3a-b); these samples were initially designed with this structure to differentiate the three layers, and as a way to help center them in the compaction device. The comparison between Fig. 3a and b also shows a slight shrinkage in the outer shell, which is most likely a consequence of a porosity reduction during sintering.
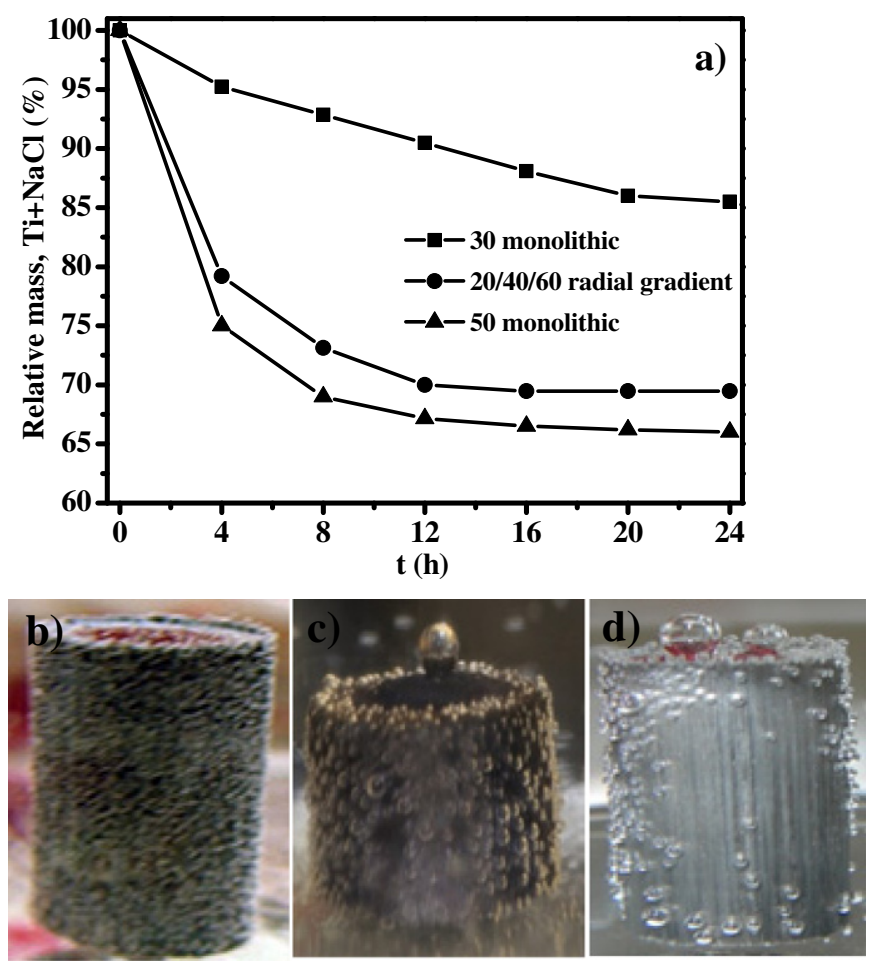

Fig. 2. a) Evaluation of mass loss corresponding to the $\mathrm{NaCl}$ removal process in function of immersion time ( $4 \mathrm{~h}$ per cycle) in distilled water for Ti cylinders with radial graded porosity developed in this work (circle symbols), homogeneous Ti cylinders with 30\% and $50 \%$ of volumetric porosity (square and triangle symbols, respectively). b-d) the corresponding images of Ti cylinder with porosity of 30\% (b), 20/40/60 radial graded porosity (c) and $50 \%(d)$. 

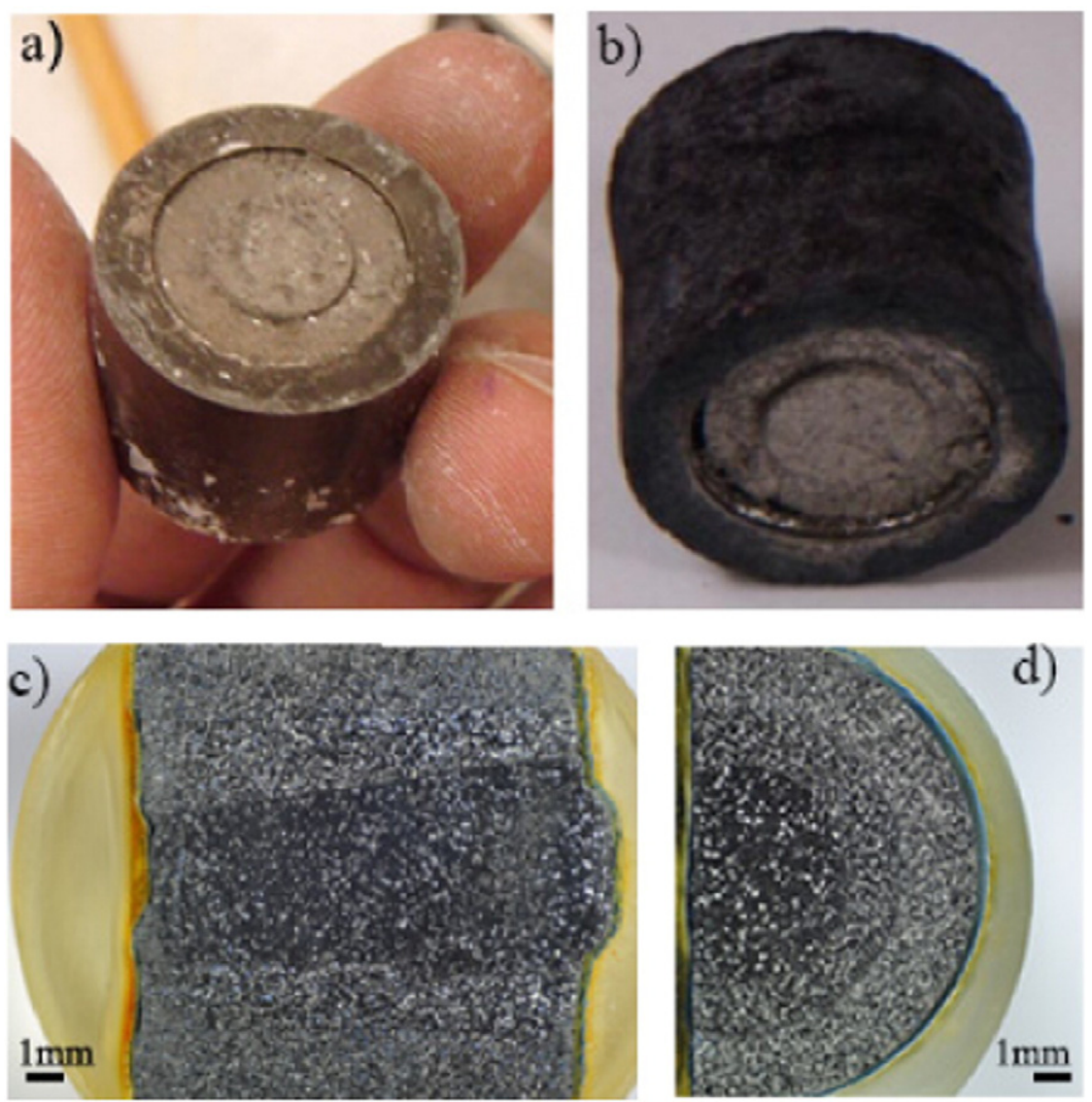

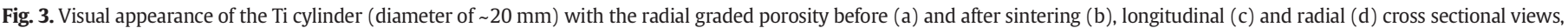
after polishing.

In order to have an overview for complete characterization, both longitudinal and cross-sectional cuts were performed across the middle axes of the sintered specimens. After those samples were polished (Fig. 3c and d), a good structural integrity was observed, without any cracks or other kind of flaws associated with poor wax removal. In the same context, a different porosity percentage within the three layers was observed, with flawless interfaces between them. Optimal alignment and centering of the layers were also noticeable, which are important factors in promoting uniform mechanical properties across the layers. The observed high interface quality and alignment of layers have served to corroborate the proper optimization of sintering conditions, as well as the $\mathrm{NaCl}$ removal protocol and the sequential compaction steps.

The density estimation by Archimedes' method is shown in Table 2 . These values were compared with density calculated by the rule of mixtures. The mismatch between both values, around $10 \%$ higher for experimental values, depends on the effect of the following factors. Experimental values could be increased by: a) the possible remaining small amount of undissolved $\mathrm{NaCl}$, producing an increase of weight in the position where it was expected to develop pores after sintering. It

Table 2

Density, total and interconnected porosity of the sintered Ti cylinder with radial graded porosity, determined by the Archimedes' method and the rule of mixtures.

\begin{tabular}{llll}
\hline & Density $\left(\mathrm{g} / \mathrm{cm}^{3}\right)$ & Porosity (vol.\%) & \\
\cline { 3 - 4 } & & Total & Interconnected \\
\hline Archimedes' method & $2.58 \pm 0.02$ & $42.7 \pm 1.8$ & $39.6 \pm 2.1$ \\
Rule of mixtures & 2.36 & 46.3 & $*$ \\
\hline
\end{tabular}

* Not determined is important to note that the remaining undissolved $\mathrm{NaCl}$ is not expected to provoke detrimental effects on the implant, as this $\mathrm{NaCl}$ could be dissolved in contact with body fluids; and, b) the volume of macropores, associated with the space-holder, could diminish slightly during sintering. The experimental results could also be reduced by: a) different porosity in the interface between layers; and b) additional microporosity associated with the sintering process.

Table 2 shows that the interconnected porosity is $~ 93 \%$ of the total value, which is most likely a consequence of the high space-holder content, normally associated with the $\mathrm{NaCl}$ removal process and the sintering step. The comparison between the total porosity determined by the Archimedes' method and the rule of mixtures (Table 2) showed the mismatch between them (around 8\% lower in the experimental values), and corroborates these discussed effects regarding density estimations. The interconnected porosity has the important beneficial effect of allowing bone ingrowth into the implant, with consequent osseointegration improvement. The higher interconnected porosity is more marked in the outer shell layer because of its higher $\mathrm{NaCl}$ content, which is an additional positive effect, taking into account that this layer is in direct contact with the bone.

An XRD pattern of the sintered specimen was obtained (Fig. 4). The set of peaks observed could be clearly assigned to a Ti phase with hexagonal structure and space group symmetry $P 63 / \mathrm{mmc}$, by comparison with the reference no. 044-1294 (PDF-4 + database from the ICDD). A simulated XRD scan pattern of this reference is also shown in Fig. 4. In addition, it is important to comment that no peaks corresponding to the space-holder $(\mathrm{NaCl})$, oxygen or carbon were detected. Therefore, a negligible amount of this element or related compounds is expected. Regarding this last aspect, routine studies by Energy-dispersive X-ray Spectroscopy (EDS) in a Scanning Electron Microscope (SEM) showed insignificant amounts of carbon and oxygen $(0.5 \pm 0.4$ wt.\% and 


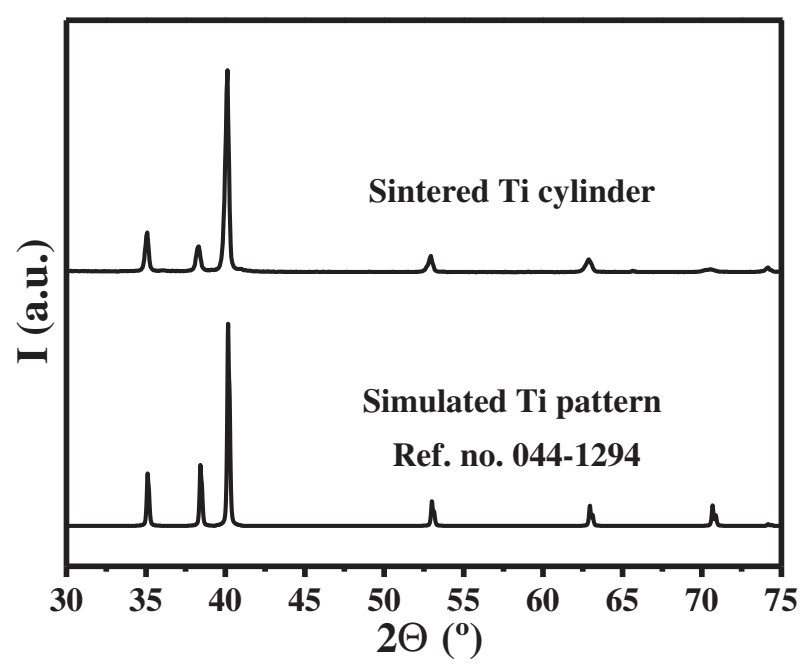

Fig. 4. XRD patterns of: a) Sintered Ti cylinder with radial graded porosity; b) Simulated Ti pattern for reference no. 044-1294 (PDF4+ database from ICDD).

$0.8 \pm 0.3$ wt.\%, respectively), corroborating the high purity of the Ti cylinders.

The assembly of images allowed the three different zones to be depicted in Fig. 5. This is the result of joining 120 micrographs obtained by optical microscopy. Once the micrographs were properly joined, IA was implemented to estimate the porosity of different zones, i.e., the core, the inner shell and the outer shell (Table 3). The porosity percentages were lower than expected, corresponding to the theoretical values, i.e., $20 \%, 40 \%$, and $60 \%$ of $\mathrm{NaCl}$ initially introduced as space-holder. This finding helped to corroborate the shrinkage phenomenon due to a reduction of porosity during sintering. This lower than expected porosity is a direct consequence of two previously mentioned factors related to the sintering step, i.e., the reduction of the inherent microporosity of the PM process in the Ti cylinder, and the collapse and size reduction of the macropores formed after $\mathrm{NaCl}$ removal. In addition, the higher deviation of the core with respect to theoretical values can be attributable to some obstacles to the removal of the space-holder $(\mathrm{NaCl})$. This can be explained by the water having to follow some tortuous paths to successfully access and dissolve $\mathrm{NaCl}$ inside all parts of the samples, through the inner and outer shells.

The optimal homogeneous distribution of porosity in each zone can also be appreciated in Fig. 5. This feature is reflected in the radial increase of porosity from the core to the outer shell, which is indicative of the effectiveness of the bio-inspired design. It must also be highlighted that interconnected porosity is basically located in the inner and outer shells, whilst the porosity in the denser core is mainly isolated.

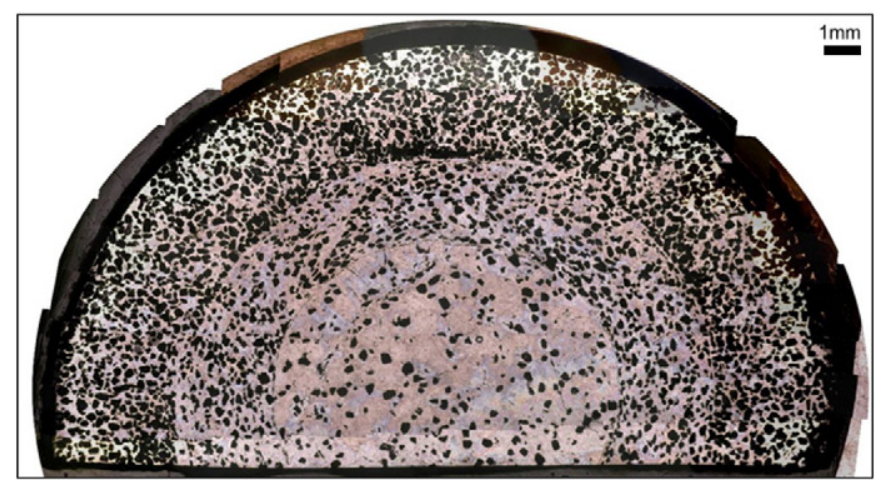

Fig. 5. Assembly of 120 optical microscope images showing a top view of a radial crosssection, and after polishing of a sintered Ti cylinder, showing the three different zones (core, inner shell and outer shell).
Table 3

Porosity percentage of each layer of the Ti cylinder, with radial graded porosity (core, inner shell and outer shell), determined by Image Analysis (IA) and X-Ray micro computed tomography $(\mathrm{CT})$. The pore size is shown as equivalent diameter of a sphere.

\begin{tabular}{llllll}
\hline Layer & Porosity & & & \multicolumn{2}{l}{$\begin{array}{l}\text { Equivalent diameter, } \mathrm{D}_{\mathrm{eq}} \\
(\mu \mathrm{m})\end{array}$} \\
\cline { 2 - 3 } \cline { 6 - 6 } & $\mathrm{IA}(\mathrm{vol} . \%)$ & $\mathrm{CT}($ vol.\%) & & IA & $\mathrm{CT}$ \\
\hline Core & $14.5 \pm 1.5$ & $10.5 \pm 3.2$ & & $142 \pm 69$ & $163 \pm 71$ \\
Inner shell & $38.3 \pm 1.2$ & $26.9 \pm 5.8$ & & $120 \pm 49$ & $134 \pm 53$ \\
Outer shell & $57.5 \pm 2.1$ & $41.2 \pm 8.1$ & & $94 \pm 29$ & $117 \pm 49$ \\
\hline
\end{tabular}

This morphological feature of higher interconnected porosity at the surface, is not only important from the biofunctional point of view, but could also be correlated with a poor structural integrity: it matches with both a bio-inspired graded porosity, with an associated lower Young's modulus, and an improvement of bone ingrowth [36]. The isolated and low porosity percentage in the core of the cylinders will help to improve mechanical properties, as will be discussed later.

It is important to point out that the above estimation of total porosity for Ti cylinders, from the relative volume and the porosity of each layer (Tables 1 and 3, respectively), allowed a value of $44.2 \%$ to be obtained. This calculation is close to that determined by Archimedes' method (42.7\%), which helped to corroborate the correct estimation of porosity.

The mean equivalent diameter of the pores, assuming spherical geometry, was determined by IA from Fig. 5, and is shown in Table 3. It is clearly observed how the pore size decreases from the core to the outer shell. Additionally, the pore size of the core (142 $\pm 69 \mu \mathrm{m})$ perfectly fits the initial $\mathrm{NaCl}$ space-holder particle size $(154 \pm 30 \mu \mathrm{m})$. These special features would indicate that sintering effectiveness is higher in the outer shell of graded samples due to a high surface energy, which is most likely a consequence of increased porosity from outer shell to the core.

The equivalent pore diameters obtained for the core, inner and outer shells had values close to $100-150 \mu \mathrm{m}$. These pore sizes were demonstrated to be optimal for ensuring a high degree of interconnectivity and, therefore, the improvement of bone ingrowth into the porous implants, which will reduce the risk of fatigue failure [36,43-45].

In order to compare all the above microstructural characteristics of Ti cylinders, a 3D rendering of samples, obtained by CT, is shown in Fig. 6, where the interfaces between core, inner and outer shells were properly removed for the analysis. The porosity values thus estimated (core: $10.5 \pm 3.2$ vol.\%; inner shell: $26.9 \pm 5.8$ vol.\% and outer shell:

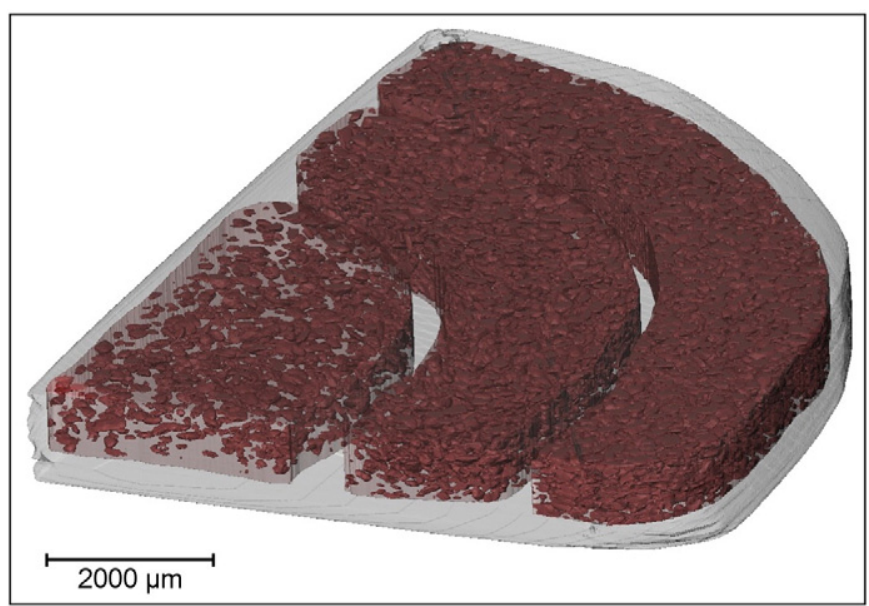

Fig. 6. 3D volume rendering of an X-ray tomography of a quarter of a cylinder of the radial graded sample showing the pores detected on each section (red) and the matrix (transparent grey). The three sections (core, inner shell and outer shell) were separated for analysis to avoid border effects at the interfaces. 


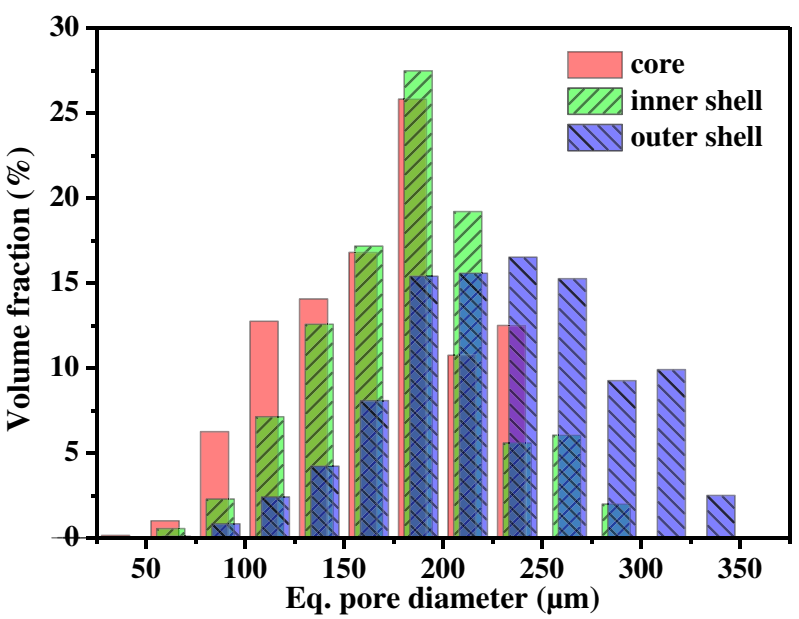

Fig. 7. Volume-weighted equivalent pore diameters distribution obtained by quantitative tomographic analysis.

$41.2 \pm 8.1$ vol.\%) were slightly lower than those obtained by IA. On the other hand, the equivalent pore diameters (core: $163 \pm 71 \mu \mathrm{m}$, inner shell: $134 \pm 53 \mu \mathrm{m}$ and outer shell: $117 \pm 49 \mu \mathrm{m}$ ) were higher than those found by using IA. Despite these differences, the general trend between those three sections is very similar, as can be seen in Table 3. The reason for the slight mismatch between IA and tomography may be found in the fundamental differences between 2D and 3D estimation methods. However, it could be due to certain factors, such as sample preparation, segmentation and separation problems, etc.

Fig. 7 shows the mean value of a log-normal distribution fit of the equivalent pore diameters for a volume-weighted distribution (core: $175 \pm 10 \mu \mathrm{m}$; inner shell: $187 \pm 4 \mu \mathrm{m}$ and outer shell: $237 \pm 5 \mu \mathrm{m}$ ). In this case, the trend for the equivalent pore diameter is opposite to those found by IA and CT direct determination (Table 3), increasing from the core to the outer shell. This is a feature that showed some interconnected pores from the outer core represent a larger volume and, therefore, they have a dominant role, instead of non-interconnected pores. This porosity characteristic cannot be properly separated by the method and it also corroborates the necessity of different analyses depending on the purposes.

\subsection{Mechanical behavior}

The yield strength of Ti cylinders was determined by a uniaxial compression test (Table 4). The typical stress-strain curve is presented in Fig. 8. It is important to note that the estimated value of this mechanical property is clearly higher than for cortical bone (279 MPa versus 150 $180 \mathrm{MPa}$ [38]), irrespective of the high porosity obtained in the Ti cylinder. This higher yield strength can be explained in terms of the lower porosity in the core, which is consistent with the observation of structural integrity of the same core after uniaxial compression testing (see inset in Fig. 8). In contrast, the outer shell was severely damaged after

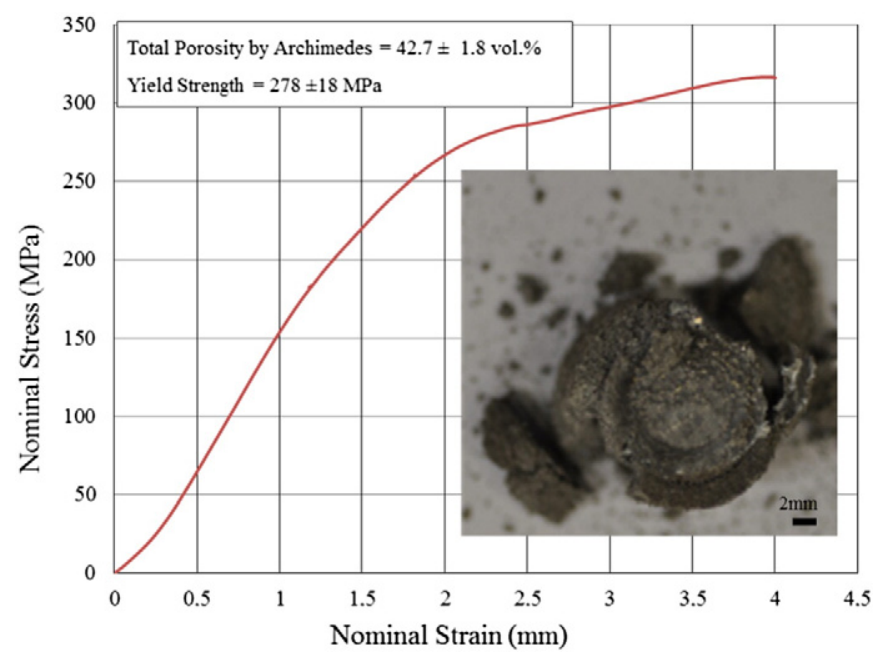

Fig. 8. Stress-strain curve and inset showing the visual aspect of the Ti cylinder, after the uniaxial compression test, and the optimal structural integrity of the core and inner shell.

testing, as can be observed in the same inset in Fig. 8. This clear difference in response could be related to the easy collapsing of the outermost interface between the inner and outer shells due to the higher interconnected porosity (see Fig. 5); in the same sense, the innermost interface, with lower porosity, between core and inner shell, allowed good structural integrity.

The yield strengths of Ti cylinders with homogeneous porosity developed with the same composition and microstructure of core, inner and outer shells, exhibited an opposite trend: 420, 235 and $110 \mathrm{MPa}$, respectively (Table 4) $[40,43]$. These values appear in good agreement with the experimental values for each zone in the Ti cylinders. Specifically, the yield strength of these same samples (279 MPa) is actually close to the value of $\mathrm{Ti}$ cylinders with a porosity of 40 vol.\% (235 MPa), close to the total porosity determined by Archimedes' method and IA (42.7 vol.\% and 44.2 vol.\%, respectively).

The dynamic Young's modulus $\left(\mathrm{E}_{d}\right)$ for the Ti cylinders was estimated by the interpolation of the total porosity on the Young's modulus measurements. These results were obtained by ultrasonic technique in the corresponding specimens with the nominal porosity expected on each layer (core, inner shell, and outer shell), i.e., 20 vol.\%, 40 vol.\% and $60 \mathrm{vol} . \%$ ( $\mathrm{E}_{d}$ from $61.3 \mathrm{GPa}$ to $14.5 \mathrm{GPa}$ ) [43]. All these values are shown in Table 4 . The stiffness, measured by ultrasonic technique, decreases with increasing porosity in agreement with Eshelby's elasticity-based theory for closed, spherical porosity.

The estimated value (26 GPa) was similar to the Young's modulus reported for cortical bone (around 20.7-18.6 GPa [14]). This good agreement between both values is an important advance in the search of the optimal biomechanical compatibility between implants and bone tissue and, therefore, contributing to reduce the usual and undesirable stressshielding phenomenon. It is important to point out that although the Ti cylinders with radial graded porosity and reduction of Young's modulus

Table 4

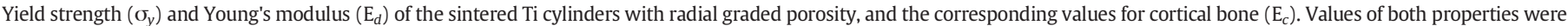
also obtained from $\mathrm{Ti}$ cylinders with the porosity of each zone $[40,43]$. Experimental $\mathrm{E}_{d}$ was obtained from the ultrasonic technique.

\begin{tabular}{|c|c|c|c|c|c|c|c|c|}
\hline & & \multicolumn{2}{|c|}{ Compression test } & \multicolumn{3}{|c|}{ Ultrasonic technique } & \multicolumn{2}{|c|}{ Cortical bone } \\
\hline & & $\mathrm{E}_{\mathrm{c}}(\mathrm{GPa})$ & $\sigma_{\mathrm{y}}(\mathrm{MPa})$ & $\mathrm{E}_{d}$ (Exp.) & $\mathrm{E}_{d}$ (Est.) & & $\mathrm{E}_{\mathrm{c}}(\mathrm{GPa})$ & $\sigma_{y}(\mathrm{MPa})$ \\
\hline \multirow[t]{3}{*}{ Homogenous porosity } & $20 \%$ vol. $\mathrm{NaCl}$ & $18.0 \pm 1.0$ & $458 \pm 5$ & $61.3 \pm 0.5$ & $*$ & & $20-25$ & $150-180$ \\
\hline & $40 \%$ vol. $\mathrm{NaCl}$ & $14.2 \pm 1.2$ & $186 \pm 8$ & $29.0 \pm 0.7$ & & & & \\
\hline & $60 \%$ vol. $\mathrm{NaCl}$ & $12.3 \pm 1.4$ & $81 \pm 13$ & $14.1 \pm 1.0$ & & & & \\
\hline \multirow[t]{3}{*}{ Gradient } & Core & $8.3 \pm 1.9$ & $278 \pm 18$ & $*$ & $26 \pm 1.4$ & $77.5 \pm 1.2$ & & \\
\hline & Inner shell & & & & & $31.5 \pm 1.4$ & & \\
\hline & Outer shell & & & & & $11.5 \pm 1.4$ & & \\
\hline
\end{tabular}

\footnotetext{
* Not determined
} 
have been successfully obtained, the next step on the investigation would be the development of studies of real implants with the corresponding geometry. In this context, to optimize the design of the implant, a complete numerical analysis of the mechanical behavior for a radial graded porous implant interacting with the bone would be essential. Until now, Hedia et al. [46,47] have developed by FEA simulated implants with the geometric design (minimizing harmful effects such as stress shielding of the bone or high shear stress in the interface boneimplant), obtaining promising results. In addition, the authors have performed also FEA studies published [48] on cylindrical samples under tensile stress, which is an indirect validation of the stress-shielding reduction effectiveness of these samples.

By other hand, the same interpolation process as above mentioned was carried out in each layer (core, inner shell and outer shell) by taking into account their porosity determined by IA (Table 3 ). The slightly higher Young's modulus obtained, in comparison with the Ti cylinder with homogenous porosity (both series of values are presented in Table 4), can only be explained in terms of the lower porosity percentage of each layer due to decreasing micro and macroporosity (from voids formed after $\mathrm{NaCl}$ removal) during the sintering process.

It must be noted that the Young's modulus determined from uniaxial compression tests that appears in Table 4 (8.3 GPa), is considerably lower than that estimated from the Ti cylinders with homogeneous porosities $(\sim 26 \mathrm{GPa})$. This lower value is closer to trabecular bone ( $10 \mathrm{GPa}$ ), with a clear new mismatch with respect to cortical bone. This difference was already reported by the authors in some recent works [37,40], and it was attributed to deficient joined interfaces, especially at the joint of the inner-outer shells, reflected in the presence of pores, some residual stress, flaws, etc. Within this context, it must be pointed out that Ti cylinders start to collapse at the layer with higher porosity and/or lower Ti percentage (outer shell). However, the overall structural integrity is mostly dependent on both the inner shell and core strengths.

It must be remembered that the correct evaluation of Young's modulus in porous materials is still a controversial technical and scientific issue. It is typically found that Young's modulus measurements from uniaxial compression tests are lower than dynamic measurements. Greiner et al. [49] associated this discrepancy with super-elastic deformation within the linear elastic range of NiTi materials. These authors related this difference to the testing machine stiffness in which the mechanical system and sample were considered as two springs in series. Moreover, it must be remembered that the Ti matrix is different at each layer of the cylindrical sample; during a compression test the material collapse starts at the section with the lowest Ti content or higher porosity, i.e., the outer shell. The Young's modulus estimations reported here, from the compression stress-strain curves, were already corrected for the stiffness of the testing machine $(87.9 \mathrm{kN} / \mathrm{mm})$. We have reported a similar trend for c.p. Ti obtained by a conventional powder-metallurgy process [40], as well as in recent work $[37,39]$ developed with spaceholder $(\mathrm{NaCl})$. In these earlier works, the reliability and certainty of ultrasound measurements were validated by comparison with a wellknown and accepted pore-elasticity model, such as that of Nielsen [50].

\section{Conclusions}

1. A new sequential compaction device was successfully employed to reproduce the initial design of the Ti cylindrical samples with radial graded porosity through space-holder technique, guaranteeing their structural integrity.

2. The compaction device and the designed sequence of space-holder percentages allowed structurally stable cylindrical samples to be obtained with a radial graded porosity design, representing a new bioinspired/bio-mimetic approach to solving one of the most important drawbacks of Ti implants, i.e., bone resorption due to the stressshielding phenomenon while ensuring a mechanical strength similar to that of cortical bone.
3. The green bodies of cylindrical Ti samples showed great structural integrity after $\mathrm{NaCl}$ removal, as well as after sintering (high quality and mechanically stable interfaces with absence of delamination and cracks,

4. The porosity obtained (homogeneous distribution and pore size in each layer) by using a particle size distribution of the $\mathrm{NaCl}$ spaceholder of between 100 and $200 \mu \mathrm{m}$, was suitable for improving the mechanical strength, achieving the desirable reduction of Young's modulus and ensuring bone growth into the implant (ingrowth).

5. Obtaining E and $\sigma_{\mathrm{y}}$ values close to cortical bone also corroborates the optimal design applied for the development of the Ti cylinder with radial graded porosity.

\section{Acknowledgments}

This work was supported by Ministry of Economy and Competitiveness of the State General Administration of Spain under the grant MAT2015-71284-P. E. Chicardi was supported by Fondecyt under postdoctoral Project No. 3150060. The authors would like to thank the student, F.J. González García, and the technicians J. Pinto and M. Sánchez, for their assistance in microstructural and mechanical characterization and the Junta de Andalucía-FEDER (Spain) through the Project Ref. P12-TEP-1401.

\section{References}

[1] A.M. Briggs, M.J. Cross, D.G. Hoy, L. Sanchez-Riera, F.M. Blyth, A.D. Woolf, L. March, Musculoskeletal health conditions represent a global threat to healthy aging: a report for the 2015 World Health Organization world report on ageing and health, Gerontologist 56 (2016) S243-S255.

[2] S. Nemes, M. Gordon, C. Rogmark, O. Rolfson, Projections of total hip replacement in Sweden from 2013 to 2030, Acta Orthop. 85 (3) (2014) 238-243.

[3] M. Mozzati, G. Gallesio, M. Del Fabbro, Long-term (9-12 years) outcomes of titanium implants with an oxidized surface: a retrospective investigation on $209 \mathrm{im}$ plants, J. Oral Implantol. 41 (4) (2015) 437-443.

[4] D.J. Blackwood, Biomaterials: past successes and future problems, Corros. Rev. 21 (2-3) (2003) 97-124.

[5] Y. Wang, H. Yu, C. Chen, Z. Zhao, Review of the biocompatibility of micro-arc oxidation coated titanium alloys, Mater. Des. 85 (2015) 640-652.

[6] A.T. Sidambe, Biocompatibility of advanced manufactured titanium implants-a review, Materials 7 (12) (2014) 8168-8188.

[7] B. Meng, M.W. Fu, S.Q. Shi, Deformation behavior and microstructure evolution in thermal-aided mesoforming of titanium dental abutment, Mater. Des. 89 (2016) 1283-1293.

[8] R.B. Osman, M.V. Swain, A critical review of dental implant materials with an emphasis on titanium versus zirconia, Materials 8 (3) (2015) 932-958.

[9] E.D. Spoerke, N.G. Murray, H.L. Li, L.C. Brinson, D.C. Dunand, S.I. Stupp, A bioactive titanium foam scaffold for bone repair, Acta Biomater. 1 (5) (2005) 523-533.

[10] G. Ryan, A. Pandit, D.P. Apatsidis, Fabrication methods of porous metals for use in orthopaedic applications, Biomaterials 27 (13) (2006) 2651-2670.

[11] Y. Higuchi, Y. Ohashi, H. Nakajima, Biocompatibility of lotus-type stainless steel and titanium in alveolar bone, Adv. Eng. Mater. 8 (9) (2006) 907-912.

[12] F. Thorey, F. Witte, J. Nellesen, N. Griep-Raming, H. Menzel, G. Gross, A. Hoffmann, J. Seufert, H. Windhagen, Improved osseointegration of titanium implants after surface coating with polymers in a rabbit model, Orthopade 34 (11) (2005) $(1112-+)$.

[13] G. Sovak, A. Weiss, I. Gotman, E.Y. Gutmanas, SEM Evaluation of the Osteointegration of Titanium Nitride-Coated Ti-6Al-4V Alloy Implants in Rat Femurs, 1998.

[14] J.Y. Rho, R.B. Ashman, C.H. Turner, Youngs modulus of trabecular and cortical bone material - ultrasonic and microtensile measurements, J. Biomech. 26 (2) (1993) 111-119.

[15] D.R. Sumner, Long-term implant fixation and stress-shielding in total hip replacement, J. Biomech. 48 (5) (2015) 797-800.

[16] R.S. Bedi, D.E. Beving, L.P. Zanello, Y. Yan, Biocompatibility of corrosion-resistant zeolite coatings for titanium alloy biomedical implants, Acta Biomater. 5 (8) (2009) 3265-3271.

[17] J. Xiong, Y. Li, X. Wang, P. Hodgson, C.e. Wen, Mechanical properties and bioactive surface modification via alkali-heat treatment of a porous Ti-18Nb-4Sn alloy for biomedical applications, Acta Biomater. 4 (6) (2008) 1963-1968.

[18] A. Pareja-López, C.P. García-García, P.J. Abad, M.E. Márquez, Estudio in vitro de la citotoxicidad y genotoxicidad de los productos liberados del acero inoxidable 316 L con recubrimientos cerámicos bioactivos, Iatreia 20 (1) (2007) 12-20.

[19] K. Niespodziana, K. Jurczyk, J. Jakubowicz, M. Jurczyk, Fabrication and properties of titanium-hydroxyapatite nanocomposites, Mater. Chem. Phys. 123 (1) (2010) 160-165.

[20] S.L. Wu, X.M. Liu, K.W.K. Yeung, C.S. Liu, X.J. Yang, Biomimetic porous scaffolds for bone tissue engineering, Mater. Sci. Eng. R. Rep. 80 (2014) 1-36. 
[21] Q. Ye, G. He, In-situ formed graded microporous structure in titanium alloys and its effect on the mechanical properties, Mater. Des. 83 (2015) 295-300.

[22] P.S. Liu, H.B. Qing, H.L. Hou, Y.Q. Wang, Y.L. Zhang, EMI shielding and thermal conductivity of a high porosity reticular titanium foam, Mater. Des. 92 (2016) 823-828.

[23] J. Banhart, Manufacture, characterisation and application of cellular metals and metal foams, Prog. Mater. Sci. 46 (6) (2001) (559-U3)

[24] A. Bansiddhi, T.D. Sargeant, S.I. Stupp, D.C. Dunand, Porous NiTi for bone implants: a review, Acta Biomater. 4 (4) (2008) 773-782.

[25] C. Betts, Benefits of metal foams and developments in modelling techniques to assess their materials behaviour: a review, Mater. Sci. Technol. 28 (2) (2012) 129-143.

[26] R. Singh, P.D. Lee, R.J. Dashwood, T.C. Lindley, Titanium foams for biomedical applications: a review, Mater. Technol. 25 (3-4) (2010) 127-136.

[27] B. Bertheville, Porous single-phase NiTi processed under Ca reducing vapor for use as a bone graft substitute, Biomaterials 27 (8) (2006) 1246-1250.

[28] S.L. Zhu, X.J. Yang, D.H. Fu, L.Y. Zhang, C.Y. Li, Z.D. Cui, Stress-strain behavior of porous NiTi alloys prepared by powders sintering, Mater. Sci. Eng. A Struct. Mater Prop. Microstruct. Process. 408 (1-2) (2005) 264-268.

[29] M. Nicoara, A. Raduta, R. Parthiban, C. Locovei, J. Eckert, M. Stoica, Low Young's modulus Ti-based porous bulk glassy alloy without cytotoxic elements, Acta Biomater. 36 (2016) 323-331.

[30] M. Koehl, T. Habijan, M. Bram, H.P. Buchkremer, D. Stoever, M. Koeller, Powder metallurgical near-net-shape fabrication of porous NiTi shape memory alloys for use as long-term implants by the combination of the metal injection molding process with the space-holder technique, Adv. Eng. Mater. 11 (12) (2009) 959-968.

[31] X. Jian, C. Hao, Q. Guibao, Y. Yang, L. Xuewei, Investigation on relationship between porosity and spacer content of titanium foams, Mater. Des. 88 (2015) 132-137.

[32] M.C. Melican, Y. Li, K.R. Brown, I. Chun, A. Rezania, A.G. Scopellianos, M.N. Vyakarnam, J. McAllen, Biocompatible tissue implant for repairing tissue tear such as soft tissue injury, comprises bioabsorbable polymeric foam component, an reinforcing component formed of biocompatible mesh-containing material, Ethicon Inc, 2008.

[33] O. Carvalho, M. Buciumeanu, G. Miranda, S. Madeira, F.S. Silva, Development of a method to produce FGMs by controlling the reinforcement distribution, Mater. Des. 92 (2016) 233-239.

[34] I.H. Oh, H. Segawa, N. Nomura, S. Hanada, Microstructures and mechanical properties of porosity-graded pure titanium compacts, Mater. Trans. 44 (4) (2003) 657-660.

[35] Y. Torres, P. Trueba, J. Pavón, I. Montealegre, J.A. Rodríguez-Ortiz, Designing, processing and characterisation of titanium cylinders with graded porosity: an alternative to stress-shielding solutions, Mater. Des. 63 (2014) 316-324.

[36] T. Traini, C. Mangano, R.L. Sammons, F. Mangano, A. Macchi, A. Piattelli, Direct laser metal sintering as a new approach to fabrication of an isoelastic functionally graded material for manufacture of porous titanium dental implants, Dent. Mater. 24 (11) (2008) 1525-1533.

[37] Y. Torres, J.J. Pavon, J.A. Rodriguez, Processing and characterization of porous titanium for implants by using $\mathrm{NaCl}$ as space holder, J. Mater. Process. Technol. 212 (5) (2012) 1061-1069.

[38] Y. Torres, J.A. Rodriguez, S. Arias, M. Echeverry, S. Robledo, V. Amigo, J.J. Pavon, Processing, characterization and biological testing of porous titanium obtained by space-holder technique, J. Mater. Sci. 47 (18) (2012) 6565-6576.

[39] J.J. Pavon, P. Trueba, J.A. Rodriguez-Ortiz, Y. Torres, Development of new titanium implants with longitudinal gradient porosity by space-holder technique, J. Mater. Sci. 50 (18) (2015) 6103-6112.

[40] Y. Torres, J.J. Pavon, I. Nieto, J.A. Rodriguez, Conventional powder metallurgy process and characterization of porous titanium for biomedical applications, Metall. Mater. Trans. B Process Metall. Mater. Process. Sci. 42 (4) (2011) 891-900.

[41] W.E. Luecke, L. Ma, S.M. Graham, M.A. Adler, Repeatability and Reproducibility of Compression Strength Measurements Conducted According to ASTM E9, NIST Technical Note 1679, 2009.

[42] J. Müller-Rochholz, Determination of the elastic properties of lightweight aggregate by ultrasonic pulse velocity measurement, Int. J. Cem. Compos. Light. Concr. 1 (2) (1979) 87-90.

[43] Y. Torres, S. Lascano, J. Bris, J. Pavon, J.A. Rodriguez, Development of porous titanium for biomedical applications: a comparison between loose sintering and space-holder techniques, Mater. Sci. Eng. C Mater. Biol. Appl. 37 (2014) 148-155.

[44] R. Singh, P.D. Lee, T.C. Lindley, R.J. Dashwood, E. Ferrie, T. Imwinkelried, Characterization of the structure and permeability of titanium foams for spinal fusion devices, Acta Biomater. 5 (1) (2009) 477-487.

[45] A.R. Boccaccini, V. Maquet, Bioresorbable and bioactive polymer/Bioglass ${ }^{\circledR}$ composites with tailored pore structure for tissue engineering applications, Compos. Sci. Technol. 63 (16) (2003) 2417-2429.

[46] H.S. Hedia, N. Fouda, Design optimization of cementless hip prosthesis coating through functionally graded material, Comput. Mater. Sci. 87 (2014) 83-87.

[47] H.S. Hedia, S.M. Aldousari, A.K. Abdellatif, N. Fouda, A new design of cemented stem using functionally graded materials (FGM), Biomed. Mater. Eng. 24 (3) (2014) 1575-1588.

[48] S. Munoz, J. Pavon, J.A. Rodriguez-Ortiz, A. Civantos, J.P. Allain, Y. Torres, On the influence of space holder in the development of porous titanium implants: mechanical, computational and biological evaluation, Mater. Charact. 108 (2015) 68-78.

[49] C. Greiner, S.M. Oppenheimer, D.C. Dunand, High strength, low stiffness, porous NiTi with superelastic properties, Acta Biomater. 1 (6) (2005) 705-716.

[50] L.F. Nielsen, Elasticity and damping of porous materials and impregnated materials, J. Am. Ceram. Soc. 67 (2) (1984) 93-98. 